\title{
PRELIMINARY FINDINGS ON BEHAVIORAL PATTERNS OF THE BARKING DEER, MUNTIACUS MUNTJAK (ZIMMERMANN 1780) IN CAPTIVITY AT DHAKA ZOO IN BANGLADESH
}

\author{
MAHRUMA AKTAR, RASEL AHAMMED ${ }^{1}$, M. MONIRUL H. KHAN \\ AND M. M. KABIR \\ Department of Zoology, Jahangirnagar University, Savar, Dhaka 1342, Bangladesh \\ ${ }^{1}$ IUCN Bangladesh Country Office, House 16, Road 2/3, Banani, Dhaka 1213, \\ Bangladesh
}

\begin{abstract}
This research was conducted to document behavioral patterns of the barking deer, Muntiacus muntjak (Zimmermann 1780) in captivity. All-occurrence and ad libitum sampling methods were used opportunistically to observe 15 barking deer at Dhaka Zoo in Bangladesh from April to November, 2011. A total of 54 behavioral patterns of the barking deer was recorded and described under 13 major heads. Of which, 41 behavioral patterns were similar for males and females and 13 were sex different. The highest observation was recorded for self-directed behaviors $(21.55 \%)$ followed by consuming behaviors $(20.84 \%)$, investigative behaviors $(17.65 \%)$, scent markings and depositions (14.53\%), relaxed states (13.98\%), agonistic interactions (2.63\%), foraging behaviors $(2.31 \%)$, sexual behaviors $(1.83 \%)$, submissive behaviors (1.66\%), elimination $(1.25 \%)$, movements $(1.23 \%)$, vocalization $(0.3 \%)$ and affinitive interactions $(0.23 \%)$. The behavioral patterns were almost similar for male and female with several patterns showing variations. Females consumed food and took rest more frequently than males, who spent more time in foraging and movement. Males also showed higher frequency of sexual behaviors and less submissive behaviors. Environmental sniffing $(n=792)$ was the most frequently encountered behavior and preaching $(n=1)$ was the least. The present findings reveal that majority of the behaviors resemble that of other cervids, but nibbling and barking are unique to this species.
\end{abstract}

Key words: Barking deer, Behavioral patterns, Dhaka Zoo, Bangladesh

\section{Introduction}

A comprehensive knowledge of the basic behavioral patterns is needed for understanding the social interactions of an animal (Torr and Shine 1994). Behavior is likely to vary with individuals and age- sexes; as such, an understanding of sex specific behavior traits may assist in improving management techniques and practices (Lu et al. 2009). The classification and description of an animal's behavior is fundamental to quantitative ethological studies (MacNulty et al. 2007). Behavioral variation in ungulate populations is an area of research, which could provide -insights not only into the evolution of ungulate behavior, but also more generally into the evolution of the process in individual decision making (Isvaran 2005). 
The barking deer, Muntiacus muntjak (Zimmermann 1780) is a small solitary species that occur in forested habitats in tropical Asia (James et al. 2008). They are of great interest to evolutionary biologists and cytogeneticists because of the considerable diversity of their karyotypes, despite their' morphological similarity (Fontana and Rubini 1990). In common with other ruminants barking deer becomes a basic food for a long range of carnivores, thus act an important component of food chain of forest ecosystem (Prater 1971). It is an endangered species in Bangladesh (IUCN Bangladesh 2003). Therefore, it is necessary to conserve this species for a healthy forest ecosystem. In this context, there is a need to understand the scientific knowledge on ecology, behavior and biology.

The available literature on behavior of the barking deer in Bangladesh is rare and imprecise (Ahammed et al. 2013). For better management and conservation of this species, a thorough understanding of behavioral characteristics is required. The present study was designed to know the behavioral patterns of barking deer in captivity which may be useful in management practices of this species in both captivity and wild.

\section{Material and Methods}

Study area: The study was conducted at Dhaka Zoo $\left(23^{\circ} 41^{\prime}-23^{\circ} 46^{\prime} \mathrm{N}\right.$ latitudes and $90^{\circ} 22^{\prime}-$ $90^{\circ} 26^{\prime} \mathrm{E}$ longitudes) situated at Mirpur, Dhaka. It covers an area of 75.5 ha. Topographically, the zoo area is more or less plain land with loamy and sandy soils. Rainfall and temperature patterns delimit the annual cycle into three distinct periods: hot and humid summer from March to May, monsoon from June to October, and cool and dry winter from November to February (Ahmad 1968). The zoo area has diverse vegetation types including both exotic and indigenous. The vegetation supports many wild animals (e.g., squirrel, mongoose, myna, monitor lizard, etc).

Animal enclosure: The experimental animals were in an enclosure $(14.6 \times 28.9 \mathrm{~m})$, surrounded by iron bars of about $2.13 \mathrm{~m}$ high. The enclosure provided semi-natural habitat for deer with native grasses (e.g., Axonopus compressus and Cynodon dactylon), and large shading trees (e.g., Ficus religiosa). It contained feed for providing supplementary food, freshwater tank and a small 'box' shelter for protection during inclement weather.

Experimental animals: Data were collected from 15 ( 8 adult males, 4 adult females and 3 sub-adult females) barking deer. Age groups of barking deer were distinguished by following Pokharel and Chalise (2010). The age-sex classes of deer were determined by direct sighting based on Hendrichs (1975).

Behavior recording methods: The experimental animals were observed for 150 hours in 18 days from April to November in 2011. During the intensive study, only the diurnal behavior patterns were recorded at 15 -minutes sampling period by using all-occurrence sampling method opportunistically as described by Altmann (1974). Special behavior of deer, which was missed in the sampling period, was recorded as ad libitum. The behavior 
patterns of captive barking deer were recorded and described under thirteen categories: foraging behavior, consuming behavior, movement, relaxed state, investigative behavior, self-directed behavior, affinitive interaction, agonistic interaction, submissive behavior, sexual behavior, scent marking and deposition, vocalization and elimination, but the categories are not mutually exclusive. Video camera was used when needed, photographs were taken using digital camera and observations were recorded.

Ethogram: An ethogram when is a set of terms and descriptions of the behavior of an animal may be comprehensive of all behaviors of a species or it may be for only one sex, age group or type of behavior (Lehner 1987). It spells out the biological roots and meanings of animal actions and gives up a catalogue of behavioral patterns. On the basis of previous behavioral studies on different deer species by MacNamara and Eldridge (1987), Lu et al. (2009), Savanth et al. (2011), Ahammed et al. (2013) and preliminary observations, the ethogram was constructed for this study on barking deer (Table1).

Data analysis: Behaviors were quantified by counting the number of events (frequency or rate measures) (Altmann 1974). Graphical representation was prepared by using MSExcel software (Ver. 2007).

Table 1. Ethogram used for collecting behavioral data of barking deer in captivity at Dhaka Zoo.

\begin{tabular}{|c|c|}
\hline Behavioral categories & Description \\
\hline Foraging $(\mathrm{FG})$ & Searching for food \\
\hline Consuming (CO) & Taking food or water for survival \\
\hline Movement (MV) & Changing location \\
\hline Relaxed state (RS) & Animal is in inactive state \\
\hline Investigative (IV) & Response to stimuli or potential stimuli \\
\hline Self-directed behavior (SD) & Animal exhibits activities directed to itself \\
\hline Affinitive interaction (AI) & $\begin{array}{l}\text { Direct physical contact between individuals, without obvious } \\
\text { conflict }\end{array}$ \\
\hline Agonistic interaction (AG) & $\begin{array}{l}\text { Obvious aggressive behaviors with or without } \\
\text { direct body contact }\end{array}$ \\
\hline Submissive behavior (SB) & $\begin{array}{l}\text { The behaviors of an inferior animal when approached by a } \\
\text { dominant animal. }\end{array}$ \\
\hline Sexual (SE) & Bëhaviors related attract opposite sex for reproduction \\
\hline $\begin{array}{l}\text { Scent marking \& deposition } \\
\text { (MD) }\end{array}$ & Behaviors associated with exploring a new area or an object \\
\hline Vocalization (VO) & $\begin{array}{l}\text { Gives calls usually on sensing a predator or during withdrawal to } \\
\text { an approaching male who attempt to mount. }\end{array}$ \\
\hline Elimination (EL) & Release urine or feces from body \\
\hline
\end{tabular}

\section{Results and Discussion}

A total of 54 behavior patterns of barking deer under 13 major heads was recorded in captivity, of which 41 behavioral patterns were similar in both males and females and 13 showed sex difference (Table 2). The highest frequency $(21.55 \%)$ was recorded for self directed behavior and the lowest ( $0.23 \%$ ) was affinitive interaction (Fig. 1$)$. 


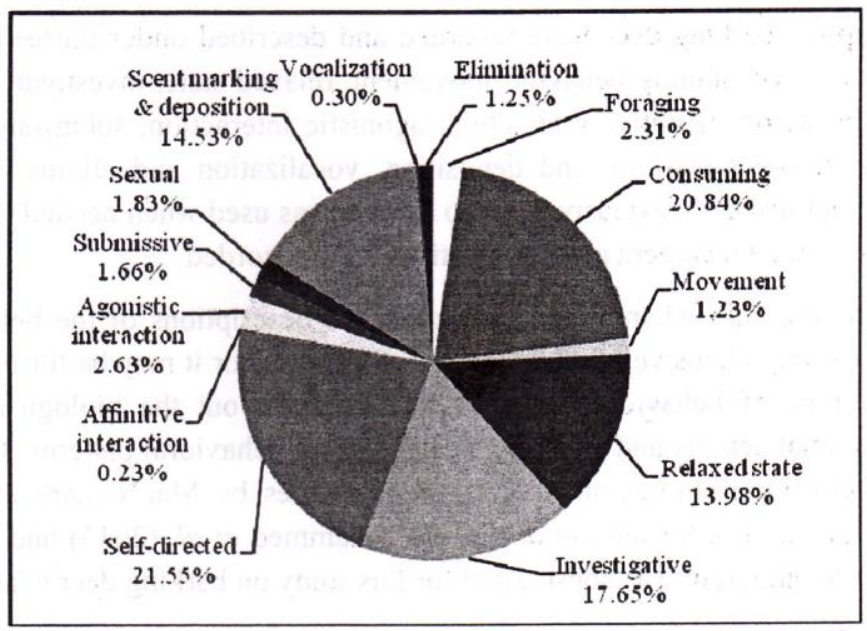

Fig.1. Percentage of time spent in major behavioral categories by barking deer at Dhaka Zoo.

Females consumed food and rested more frequently than males, while male spent more time in foraging and movement. Males also showed higher frequency of sexual and less frequency of submissive behaviors than females. All other behavior categories showed relatively similar frequency between males and females (Fig. 2). In captivity, environmental sniffing $(n=792)$ was the most frequently encountered behavior. Other more frequently encountered behavior patterns were sitting $(n=719)$, self lick $(n=599)$, ear movement $(n=560)$, tail movement $(n=460)$, scanning $(n=369)$, etc (Table 2$)$.

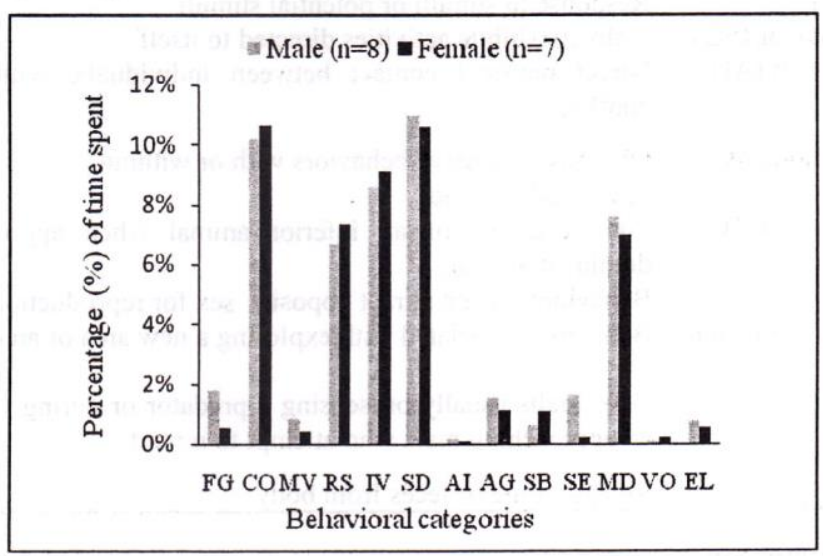

Fig. 2. Time spent in major behavioral categories by male and female barking deer at Dhaka Zoo.

Note: FG-foraging, CO-consuming, MV-movement, RS-relaxed state, IV-investigative, SD-selfdirected behaviour, AI-affinitive interaction, AG-agonistic interaction, SB-submissive behavior, SE-sexual, MD-scent marking and deposition, VO-vocalization and ELelimination. 
This study shows that barking deer perform 54 behavioral patterns with their essential maintenance behavior, social encounters and interactions with environment. The deer were less active and spent most of the time in self-directed behaviors followed by consuming behaviors, investigative behaviors and scent markings and depositions. The frequency of behaviors was almost similar for male and female barking deer in captivity and with variations of several behavioral patterns. Our preliminary observations reveal that majority of the behaviors resemble that of other cervids, but several patterns (e.g., nibbling, barking) are unique to this species.

Table 2. Behavioral patterns observed on barking deer in captivity at Dhaka Zoo.

\begin{tabular}{|c|c|c|c|}
\hline \multirow{2}{*}{$\begin{array}{l}\text { Behavioral } \\
\text { Categories }\end{array}$} & \multirow{2}{*}{$\begin{array}{l}\text { Behavior } \\
\text { patterns }\end{array}$} & \multicolumn{2}{|c|}{ Number and (\%) } \\
\hline & & Male & Female \\
\hline \multirow[t]{5}{*}{ Foraging } & Grazing & $6(0.20)$ & $4(0.14)$ \\
\hline & Browsing & $12(0.41)$ & $6(0.22)$ \\
\hline & Nibbling & $82(2.82)$ & $20(0.72)$ \\
\hline & Preaching & $0(0)$ & $1(0.03)$ \\
\hline & Feeding & $271(9.33)$ & $282(10.18)$ \\
\hline \multirow[t]{2}{*}{ Consuming } & Drinking & $86(2.96)$ & $90(3.25)$ \\
\hline & Ruminating & $221(7.62)$ & $232(8.38)$ \\
\hline \multirow[t]{2}{*}{ Movement } & Walking & $43(1.48)$ & $23(0.83)$ \\
\hline & Running & $3(0.10)$ & $1(0.03)$ \\
\hline \multirow[t]{3}{*}{ Relaxed state } & Standing & 34 (1.17) & $30(1.08)$ \\
\hline & Sitting & $338(11.64)$ & 381 (13.76) \\
\hline & Sleeping & $7(0.24)$ & $3(0.10)$ \\
\hline \multirow[t]{4}{*}{ Investigative } & $\begin{array}{l}\text { Flehmen } \\
\text { (Environmental) }\end{array}$ & $28(0.96)$ & $21(0.76)$ \\
\hline & Scanning & $176(6.06)$ & $193(6.97)$ \\
\hline & Ear movement & $270(9.30)$ & $290(10.47)$ \\
\hline & $\begin{array}{l}\text { Bite and lick } \\
\text { object }\end{array}$ & $12(0.41)$ & $11(0.39)$ \\
\hline \multirow[t]{5}{*}{ Self-directed } & Self lick & $302(10.40)$ & $297(10.72)$ \\
\hline & Self comb & $30(1.03)$ & $48(1.73)$ \\
\hline & Self scratch & $19(0.65)$ & $13(0.46)$ \\
\hline & $\begin{array}{l}\text { Shake head and } \\
\text { body }\end{array}$ & $36(1.24)$ & $17(0.61)$ \\
\hline & Tail movement & $233(8.02)$ & $227(8.10)$ \\
\hline \multirow[t]{2}{*}{$\begin{array}{l}\text { Affinitive } \\
\text { interaction }\end{array}$} & $\begin{array}{l}\text { Lick body } \\
\text { (conspecifics) }\end{array}$ & $6(0.20)$ & $2(0.07)$ \\
\hline & Playing & $3(0.10)$ & $2(0.07)$ \\
\hline \multirow{7}{*}{$\begin{array}{l}\text { Agonistic } \\
\text { interaction }\end{array}$} & Sparring & $4(0.13)$ & - \\
\hline & $\begin{array}{l}\text { Force up } \\
\text { without contact }\end{array}$ & $12(0.41)$ & $6(0.22)$ \\
\hline & Poke with nose & $10(0.34)$ & $12(0.43)$ \\
\hline & $\begin{array}{l}\text { Poke with } \\
\text { antlers }\end{array}$ & $5(0.17)$ & - \\
\hline & Head low & $14(0.48)$ & $7(0.25)$ \\
\hline & Attempt to bite & $6(0.20)$ & $4(0.14)$ \\
\hline & Bite & $3(0.10)$ & $2(0.07)$ \\
\hline
\end{tabular}




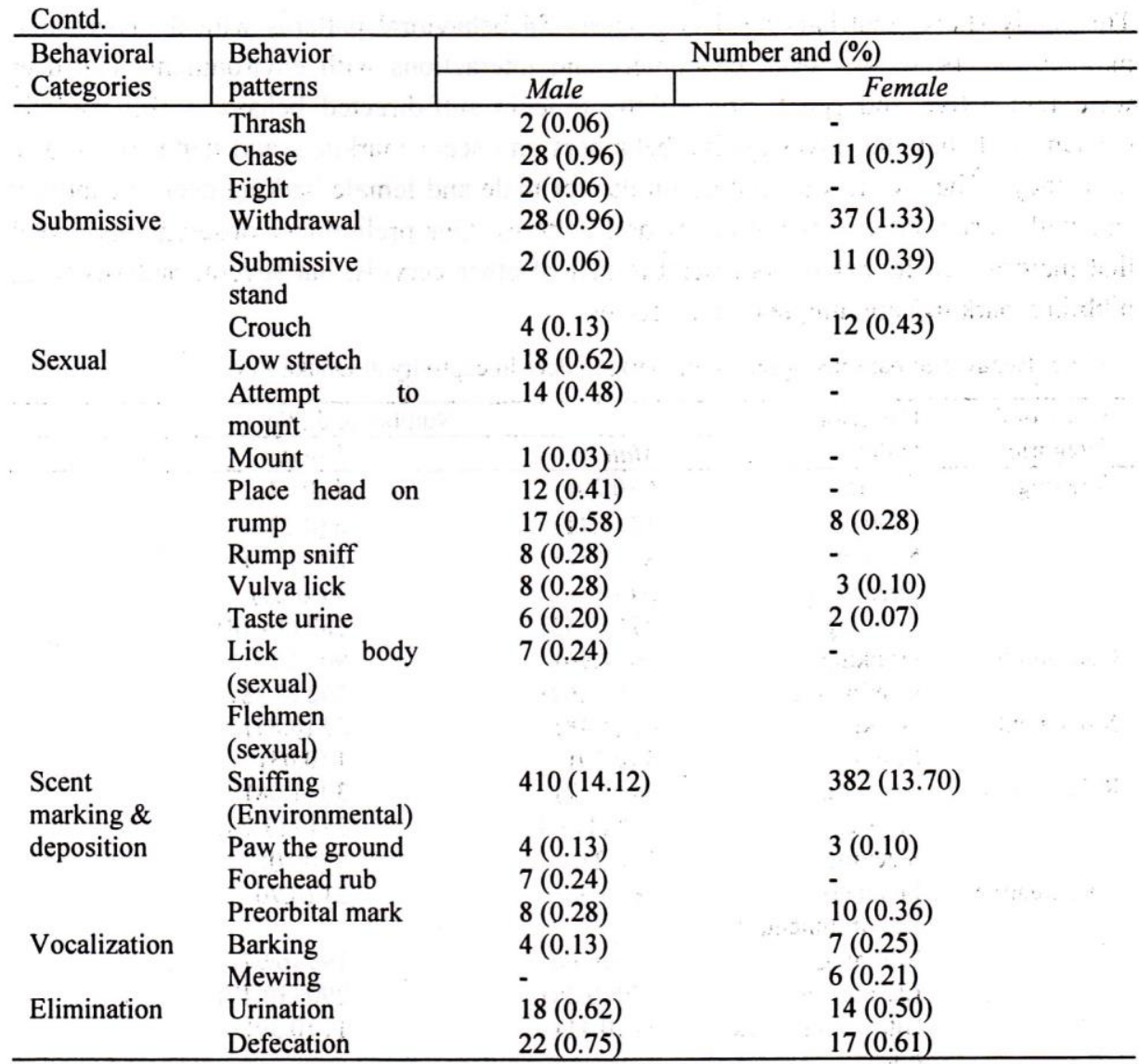

Foraging behavior: In enclosure the barking deer was observed to forage by means of grazing, browsing, nibbling and preaching. Preaching, a special foraging behavior was recorded once in eight months study period, when an individual stood erect on his hind legs and shakes its head back and forth in the leaves or exposed twigs of a low hanging branch with hind legs to remain upright. All the observed foraging behavior of barking deer is found in other cervids except nibbling and the patterns were little bit different. The nibbling behavior was also previously reported by Hofmann and Stewart (1972) and Barrette (1987).

Consuming behavior: The deer was observed to search and eat natural grass, fallen fruits or leaves of the shading tree from the floor along with supplementary food. After foraging or feeding the deer was found to ruminate and this included series of rumination of herbivores i.e., chewing, masticating and swallowing. The present findings are supported by Loe et al. (2007), who reported the main activity pattern of ruminants consists of sequential series of foraging or feeding and rumination. 
Movement: During walking the deer typically involved slowly and cautiously, frequently pausing and standing still. The males were observed to a short run, usually after resting, feeding and defecation. Typical running was observed during chasing. Similar movement patterns were reported by Kamruzzaman (2009).

Relaxed state: The deer often took rest in a standing position, remained motionless, staring straight ahead and with the head in an upward and the legs straight. They sat in stretch position and the front feet are often tucked under the body, but sometimes extended in front of the animal. They sleep in a loose curl, where the head is bent into a semicircle and attached with the neck. Almost similar resting patterns in captive Pudu pudu and Mazama americana were recorded by MacNamara and Elridge (1987).

Investigative behavior: Both male and female performed flehmen to investigate environment by raising head vertically for a short duration (about 10- 30 seconds) as reported in Pudu pudu and Mazama americana (MacNamara and Eldridge 1987). Deer was observed to scan usually during feeding and hearing sudden loud sound. They were always alert for any sound detection. Bite and lick object was primarily seen during investigation of new areas or objects that had been previously licked.

Self-directed behavior: It was found that the deer lick their body and preorbital gland most frequently, comb their fur with their incisors and scratch their body with their hind hooves. They were noted to shake their head and bodies usually after feeding, sitting and sleeping. Higher frequency of tail movement was observed usually after resting, feeding, walking and during flies disturbance. All the comfort self- directed behaviors were previously reported by $\mathrm{Lu}$ et al. (2009) in captive Moschus chrysogaster and by MacNamara and Eldridge (1987) in captive Pudu pudu and Mazama americana.

Affinitive interaction: Both male and female licked their body to one another. Males more frequently licked female's body, while female licked male's body during rutting. The most prevalent form of mutual play was chasing.

Agonistic interaction: Sparring was a harmless form of combat which typically occurred between two unequal males or between two relatively small- antlered males. Dominant males and females forced up without contact to subordinate individuals that were bedded down. During an agonistic encounter, animal poked subordinates with the nose, occasionally lifting the animal off its feet. Males also poked subordinates (both males and females) with their antlers, usually in the side or rump. It varied in intensity from a harmless slow, gentle push with the antler tips to a rapid, sometimes damaging jab. During head low, the animal remained motionless with legs stiffly erect and body at maximum height. Bumping the head against the body or head of an opponent was observed primarily during female- female interactions. Thrashing consists of swinging the head from side to side and forcefully striking the ground or vegetation with the head or antlers. This is an aggressive male who rubbed forehead prior to agonistic encounters. Chasing $(n=39)$ was the most commonly observed aggressive patterns in barking deer. 
Dominant muntjacs chased subordinates at a full run many times around the enclosure. It was observed in both sexes. Fighting was complex and consisted of a series of elements seen only during violent agonistic interaction that were often damaging to other individuals. Fights included chasing and antler- to- antler contact. All the recorded aggressive patterns observed in this study are more or less similar to the previous findings on muntjacs (Barrette 1975 and 1977a), Cervus duvaucelii (Schaller 1967 and Martin 1977) and captive Pudu pudu and Mazama americana (MacNamara and Eldridge 1987).

Submissive behavior: Withdrawal was the most common $(n=65)$ observed form of submission in barking deer. Crouch was a submissive posture in which the inferior animal remained motionless when approached by a dominant animal. Submissive stand consisted of a lowered head and slightly crouched posture while remaining motionless and avoiding eye contact. Similar submissive patterns were reported by MacNamara and Elridge (1987) in captive Pudu pudu and Mazama americana.

Sexual behavior: The low stretch consisted of several elements and was directed only by males to females. In a low stretch approach, the male walked rapidly toward a female, usually from behind with his at or below the horizontal position. When a female was near estrus, the male often placed his head on the female's rump or back after vulva lick and flehmen. It often occurred before mounting, the female usually walked away from the male. Males and females smelled the rump and perianal region of conspecifics. Male licked vulva, when following or standing close to a female who appeared to be in estrus and did not withdraw. Males usually performed flehmen in response to urine. It was performed by males during sexual encounters. Flehmen was associated with ano- genital sniffing. The male stood up on his hind legs and attempted to straddle the female with the front legs. The female either withdrew or crouched and prevented a successful mounts. The recorded sexual behavior in the study are almost similar to the previous findings on Muntiacus (Barrette 1975), captive Pudu pudu and Mazama americana (MacNamara and Eldridge, 1987) and Cervus elaphus nannodes (McCullough 1969).

Scent marking and deposition: The deer investigated a new area, wall of the enclosure, ground or an object by sniffing. In marking with preorbital glands the deer opened preorbital glands carefully to check an object. It is usually combined with forehead rubbing, sniffing, liking and flehmen. Both males and females paw the ground by repeatedly striking and pulling the forefoot sharply across the substrate, digging into the soil and sometimes uprooting grass.

Both sexes rubed their forehead against the objects. It is a means of scent deposition by the sudoriferous glands in the forehead. Scent marking and deposition patterns are typical to other cervids and similar patterns were reported by Quay and Muller-Schwarze (1970) in Antilocapra americana, C. capreolus and Odocoileus hemionus, and by MacNamara and Eldridge (1987) in captive Pudu pudu and Mazama americana. 
Vocalization: Both male and female gave calls similar to barking i.e., the sounds of bark of a dog, usually on sensing a predator was recorded. Similar findings were reported by Khan (2008) and Kamruzzaman (2009). Female produced mewing sounds during withdrawal to an approaching male who attempted to mount, which supported by Oli and Jacobson (1995).

Elimination: The deer was observed to defecate throughout their enclosure without regard to existing pellet groups and they repeatedly use specific areas, which were latrines. Barrette (1975) also reported similar observation in barking deer.

Wildlife has evolved in a unique array of behavioral characteristics that have contributed to their survival and reproduction in specialized environmental niches (Lu et al. 2009). In captivity, behavior provides an essential mean by which animals can exist within a confined and artificial environment (Price 1998). Such behavior analysis provides an opportunity to improve management practices. Small Solitary Forest Ruminants are especially difficult to study in the wild because they are nocturnal or crepuscular (MacNamara and Eldridge 1987). They are secretive and inhabit densely vegetated areas in the wild, thus the knowledge of their ecology, behavior and biology mainly depends on studies of captive populations (Barrette 1975 and 1977b). Moreover, the majority of ethological studies of mammals have concentrated on the more social species, especially primates and gregarious ungulates; few have been done on small, solitary forest ruminants like muntjacs, leaving a large gap in the knowledge of these species. Knowledge of its behavior may, therefore, be of major significance in understanding the evolution of behavior in more advanced and highly social ungulates. In this context, this research was attempted to document and provide a thorough understanding of the behavioral patterns of barking deer in captivity. The present study can be useful for understanding of behavioral characteristics of barking deer and to assist in providing more appropriate management practice both in wild and captivity. More intensive studies are needed both in wild and captivity to provide a sound basis for understanding the behavioral patterns of barking deer.

\section{References}

Altmann, J. 1974. Observation study of behavior: sampling methods. Behav. 49: 227-267.

Ahmad, N.1968. An Economic Geography of East Pakistan. Oxford University Press, London. pp. 56.

Ahammed, R., M. Aktar, M.M.H. Khan, and M.M. Kabir. 2013. Activity pattern, feeding and social behavior of barking deer Muntiacus muntjak (Zimmermann, 1780) in captivity. Jahangirnagar Univ. J. Biol. Sci. 2(2): 51-58.

Barrette, C. 1975. Social behavior of muntjacs. Unpublished Ph.D. dissertation, University of Calgary, Calgary, Alberta, Canada. pp. 234.

Barrette, C. 1977b. Some aspects of the behavior of muntjacs in Wilpattu National Park. Mammalia. 41:1-34.

Barrette, C. 1977a. Fighting behavior of muntjack and the evolution of antlers. Evolution. 31:169176. 
Barrette, C. 1987. The comparative behavior and ecology of chevrotains, musk deer, and morphologically conservative deer. In: Biology and Management of the Cervidae (ed. C. W. Wemmer). Smithsonian Institution Press. Washington D.C. pp. 200-213.

Fontana, F. and M. Rubini, 1990. Chromosomal evolution in Cervidae. Biosystems. 24(2):157-174.

Hendrichs, H. 1975. The status of the tiger (Panthera tigris Linn., 1758) in the Sundarbans Mangrove Forest (Bay of Bengal). Saugetierkd Mitt. 23:161-199.

Hofmann, R.R. and D.R.M. Stewart. 1972. Grazer or browser: a classification based on the stomach structure and feeding habits of east African ruminants. Mammalia. 36: 226-240.

Isvaran, K. 2005. Variation in male mating behaviour within ungulate populations: patterns and processes. Curr Sci. 89(7): 1192-1199.

IUCN Bangladesh. 2003. Bangladesher Bipanno Bannoprani (in Bangla). IUCN- The World Conservation Union. pp. 252.

James, J., U. Ramakrishnan, and A. Datta. 2008. Molecular evidence for the occurrence of the leaf deer Muntiacus putaoensis in Auronachal Prodesh, North-east India. Conserv Genet. 9: 927-931.

Kamruzzaman, M. 2009. Muntiacus muntjak (Zimmermann 1780). In: Ahmed, A.T.A., S.M.H. Kabir, M. Ahmad, Z.U. Ahmed, Z.N.T. Begum, M.A. Hassan, and M. Khondker, (eds.). Encyclopedia of flora and fauna of Bangladesh, Vol. 27. Mammals. Asiatic society of Bangladesh, Dhaka. pp. 181-182.

Khan, M.M.H. 2008. Protected Areas of Bangladesh-A Guide to Wildlife. Nishorgo Programe, Bangladesah Forest Department, Dhaka, Bangladesah. pp. 71.

Lehner, P.N. 1987. Design and execution of animal behavior research: An overview. J. Anim. Sci. 65:1213-1219.

Lu, L., P. Yan, X. I. Mang, J. Feng, H. Xu. Q. Yang and Z. Feng. 2009. Behavioral patterns of captive alpine musk deer: sex- specific behavior comparisons. Front. Agric. China. 3(3): 300-303.

Loe, L.E., C. Bonenfant, A. Mysterud, T. Severinsen, N.A. Ǿritsland, R. Langvatn, A. Stien, R.L. Irvine and N.C. Stenseth. 2007. Activity pattern of arctic reindeer in a predator- free environment: no need to keep a daily rhythm. Oecologia. 152:617-624.

MacNamara, M. and W. Eldridge. 1987. Behavior and reproduction in captive pudu (Pudu pudu) and red brocket (Mazama americana), a descriptive and comparative analysis. In: Biology and management of the cervids (ed. C. M. Wemmer). Smithsonian Institution Press, Washington D.C. pp. 371-387.

MacNulty, D.R., L.D. Mech and D.W. Smith. 2007. A proposed ethogram of large-carnivore predatory behavior, exemplified by the wolf. J. Mammal. 88(3): 595-605.

Martin, C. 1977. Status and ecology of the barasingha (Cervus duvauceli branderi) in Kanha National Park (India). J. Bombay Nat. Hist. Soc. 74:60-132.

McCullough, D.R. 1969. The tule elk: its history, behavior, and ecology. Univ. Calif. Publ. Zool. 88:1-209.

Oli, M.K. and H.A. Jacobson. 1995. Vocalizations of barking deer (Muntiacus muntjak) in Nepal. Mammalia. 59:179-186.

Pokharel, K. and M.K. Chalise. 2010. Status and distribution pattern of barking deer in Hemja VDC, Kaski. Nepal Journal of Science and Technology. 11: 223-228.

Prater, S. H. 1971. The book of Indian animals. Bombay Natural History Society. Bombay, India. pp. 280.

Price, E.O.1998. Behavioral genetics and the process of animal domestication. In: Grandin, T. (Editor). Genetics and the Behavior of Animals. Academic Press, New York. pp. 31-65.

Quay, W.B. and D. Muller- Schwarze, 1970. Functional histology of integumentary glandular regions in black- tailed deer. J. Mammal. 51: 675-694.

Savanth, V.V., P.C. Saseendran, K.S. Anil, V. Ramnath, J. Davis and A. Prasad. 2011. Observations on Sambar Rusa unicolor (Cetartiodactyla: Cervidae) stags during herd and velvet stages of antler cycle in captivity. J. Threat. Taxa. 3(10): 2128-2135. 
Schaller, G. B. 1967. The deer and the tiger: a study of wildlife in India. Chicago University Press, Chicago. pp. 37- 99.

Torr, G.A., and R. Shine. 1994. An ethogram for the small scincid lizard Lampropholis guichenoti. Amphibia-Reptilia. 15: 21-34.

(Revised copy received on 24.12.2015) 